\title{
Ischemic Monomelic Neuropathy after a Brachio-Cephalic AVF Creation: A Case Report and Review of Literature
}

\author{
Mohamad Taha \\ Department of Vascular Surgery, Mataria Teaching Hospital, GOTHI, Cairo, Egypt \\ Email:drmohtaha@gmail.com
}

How to cite this paper: Taha, M. (2017) Ischemic Monomelic Neuropathy after a Brachio-Cephalic AVF Creation: A Case Report and Review of Literature. World Journal of Cardiovascular Surgery, 7, 27-31. https://doi.org/10.4236/wjcs.2017.73004

Received: February 11, 2017

Accepted: March 11, 2017

Published: March 14, 2017

Copyright $\odot 2017$ by author and Scientific Research Publishing Inc. This work is licensed under the Creative Commons Attribution International License (CC BY 4.0).

http://creativecommons.org/licenses/by/4.0/

\section{(c) (i) Open Access}

\begin{abstract}
Ischemic monomelic neuropathy (IMN) is an under-diagnosed and disabling complication of upper extremity hemodialysis access. The hemodynamic disturbance that occurs during the time of access creation can lead to both neurologic and ischemic complications. These complications are most commonly seen following proximal procedures involving the upper limbs. Diagnosis and treatment are often delayed, and even with early intervention, neurologic dysfunction may be irreversible. IMN can lead to significant long-term disability. Almost all cases of IMN occur with brachial artery-based access, procedures and the vast majority of patients are diabetic and females. I report a case of IMN after left BC AVF operation which was treated successfully by early access ligation, providing a review of the literature.
\end{abstract}

\section{Keywords}

Ischemic Monomelic Neuropathy, Steal, Arteriovenous Fistula

\section{Introduction}

Distal ischemia is a known complication of vascular access placement in patients with end-stage renal disease. The incidence varies based on the location and type of access and patient demographics and ranges from less than $1 \%$ for radiocephalicarterio venous fistulas (AVFs) to $1 \%$ to $5 \%$ for brachiocephalic and brachiobasilic AVFs and 2\% to 6\% for arteriovenous grafts (AVGs) [1].

Symptoms can vary from mild pain or paresthesia to devastating arterial insufficiency with limb-threatening ischemia. Two distinct variants of upper extremity ischemia can be seen following the placement of AVFs or AVGs. In the typical vascular steal syndrome, distal ischemia is invariably present and mani- 
fested by symptoms such as numbness, pain, and paresthesia and clinical findings including diminished or absent pulses, delayed capillary refill, and in severe cases, impending or frank tissue necrosis in the involved extremity. Symptoms may begin immediately after access placement but may also be delayed for days, weeks, or months [2].

Ischemic monomelic neuropathy (IMN) is a distinct clinical entity involving dysfunction of multiple upper extremity peripheral nerves either predominantly or exclusively. Symptom onset is usually immediate and neurologic symptoms are dominant, often in the absence of significant clinical ischemia of the hand. Typically, the hand is warm; capillary refill is preserved, and a palpable radial or ulnar pulse or audible Doppler signal is present. Diagnosis and treatment are often delayed, and even with early intervention, neurologic dysfunction may be irreversible [3].

The term ischemic monomelic neuropathy was first used by Wilbourn and associates in 1983. Their initial report described a clinical entity with arterial insufficiency (ischemic) involving a single extremity (monomelic) and causing selective dysfunction (neuropathy) of multiple peripheral nerves [4].

IMN is a rare complication, but requires an early diagnosis and treatment. The key differentiating feature of IMN is that it occurs within hours of fistula or graft creatation. It is often disabling and irreversible but does not cause tissue necrosis [5]. K/DOQI guidelines suggest that "a diagnosis of monomelic is chemic; neuropathy is a clinical diagnosis, and immediate closure of the AVF is mandatory."

I report a case of IMN after left BC AVF operation which was treated successfully by early access ligation, providing a complete review of the literature.

\section{Case Report}

A 65-year-old Egyptian female with long standing type 2 diabetes and hypertension. She had 2-month history of hemodialysis for end stage renal disease via temporary catheters. She was admitted for a permanent hemodialysis access. On examination, blood pressure was 150/90, and pulse rate was 85/minute and regular. She had a palpable radial pulse bilaterally. No neurologic examination of the extremity was done preoperatively. Laboratory studies showed a white blood cell countof 8600/mL, hemoglobin of $9.6 \mathrm{~g} / \mathrm{dL}$, blood urea nitrogen (BUN) of 145 $\mathrm{mg} / \mathrm{dL}$, and serum creatinine of $9.6 \mathrm{mg} / \mathrm{dL}$. Pre-operative work up of the left arm consisted of a vein mapping which demonstrated a patent cephalic vein measuring $3-5 \mathrm{~mm}$. Brachial artery pressures demonstrate no arm to arm discrepancy.

The patient had surgery with a brachiocephalic AVF on the left side. Immediately after the surgery, the patient developed severe pain in her left hand. She complained of mild swelling and numbness of the left hand and reduced grip strength. One xamination, the fistula was patent and her radial pulse was palpable. The hand was warm. The movement of the thumb was weak and she could not move her other fingers. She had no hand sensation in any modality.

The neurological deficits persisted over the next two days and were noted to 
be worsening as reported by the patient.

A clinical diagnosis of IMN with signs of sensorimotor dysfunction of the nerves of the hand was made based on neurological symptoms, good pulse and warm left hand.

Nerve conduction studies were performed 3 days postoperatively and showed an increased distal latency, decreased nerve conduction velocity(denoting neuropathy) and decreased amplitude (denoting axonal loss) for the motor and sensory parts especially in the left side.

Reoperation with ligation of the AVF was performed after 5 days of fistula creation.

Post-operatively the pain disappeared with improvement in hand sensation and movement of the fingers.

\section{Review of Literature}

The term ischemic monomelic neuropathy was first used by Wilbourn and associates in 1983. Their initial report described a clinical entity with arterial insufficiency (ischemic) involving a single extremity (monomelic) and causing selective dysfunction (neuropathy) of multiple peripheral nerves [4]. Ischemic monomelic neuropathy is probably best classified as a form of steal phenomenon in which a new blood flow pattern created by the access surgery steals blood flow from distal tissue (in this case, predominantly nerve tissue). An AVF normally produces an alteration in blood flow patterns, a "physiological" steal phenomenon that is seen in forearm AVFs and in a greater incidence in elbow/upper arm AVFs. Physiological steal occurs in $73 \%$ of AVFs and $91 \%$ of AVGs [6] [7].

Distal ischemia is a known complication of vascular access placement in patients with end-stage renal disease. The incidence varies based on the location and type of access and patient demographics and ranges from less than $1 \%$ for radiocephalicart eriovenous fistulas (AVFs) to $1 \%$ to $5 \%$ for brachiocephalic and brachiobasilic AVFs and $2 \%$ to $6 \%$ for arteriovenous grafts (AVGs) [1]. Symptoms can vary from mild pain or paresthesia to devastating arterial insufficiency with limb-threatening ischemia.

Two distinct variants of upper extremity ischemia can be seen following the placement of AVFs or AVGs [3].

- The typical vascular steal syndrome.

- Ischemic monomelic neuropathy.

In Ischemic monomelic neuropathy symptom onset is usually immediate and neurologic symptoms are dominant, often in the absence of significant clinical ischemia of the hand. Typically, the hand is warm, capillary refill is preserved, and a palpable radial or ulnar pulse or audible Doppler signal is present [3].

Adequate blood supply to the nerves is vital to maintain their structure and function. IMN develops due to under-filling of the vasa nervosum after shunt surgery or proximal occlusion of a major artery in an extremity. It has been reported largely in diabetic patients with peripheral neuropathy and evidence of atherosclerotic peripheral vascular disease. Ischemic monomelic neuropathy (IMN) 
is a distal axonopathy involving sensory and motor branches of multiple nerves in an extremity. The condition usually involves axonal nerve injury and is not a demyelinating process. The muscle, skin, bone, and other tissues are spared. For some patients as this patient, the pain associated with IMN is the most disabling aspect of the disease.

\section{Diagnosis of IMN}

\subsection{Clinical Diagnosis}

IMN is a rare complication, but requires an early diagnosis and treatment.

The key differentiating feature of IMN is that it occurs within hours of fistula or graft creation. It is often disabling and irreversible but does not cause tissue necrosis. K/DOQI guidelines suggest that the diagnosis of ischemic monomelic neuropathy is a clinical diagnosis [6].

\subsection{Electro Diagnosis [8]}

Abnormalities are seen in a proximal-to-distal pattern, and the distal nerve supply is more affected. Radial, median, and ulnar sensory nerve action potentials (SNAPs) usually are absent from the respective digits. More proximal SNAPs (medial antebrachial cutaneous, lateral antebrachial cutaneous) are likely to be present. Motor nerve conduction from the median and ulnar nerves to the hand muscles is absent or has low amplitude.

Needle electromyography shows evidence for axonal loss with positive sharp waves and fibrillation potentials in the hand muscles (median and ulnar innervation). Needle electromyography is typically normal or less severe in proximal muscles (forearm and upper arm). For the diagnosis of IMN to be clear, one arm needs to demonstrate significantly more injury than the other arm.

\subsection{Treatment}

According to K/DOQI guidelines immediate closure of the AVF is mandatory.

\section{Conclusion}

Ischemic monomelic neuropathy is a rare but serious complication which should be considered in the differential diagnosis of hand dysfunction following vascular access. IMN is most commonly seen in the diabetic population. Diagnosis of ischemic monomelic neuropathy is a clinical diagnosis and immediate closure of the AV fistula is mandatory.

\section{Consent}

Written informed consent was obtained from the patient for publication of this case report.

\section{References}

[1] Morsy, A.H., Kulbaski, M., Chen, C., Isiklar, H. and Lumsden, A.B. (1998) Incidence and Characteristics of Patients with Hand Ischemia after a Hemodialysis 
Access Procedure. Journal of Surgical Research, 74, 8-10. https://doi.org/10.1006/jsre.1997.5206

[2] Redfern, A.B. and Zimmerman, N.B. (1995) Neurologic and Ischemic Complications of Upper Extremity Vascular Access for Dialysis. The Journal of Hand Surgery, 20, 199-204. https://doi.org/10.1016/S0363-5023(05)80007-3

[3] Miles, A.M. (1999) Vascular Steal Syndrome and Ischaemic Monomelic Neuropathy: Two Variants of Upper Limb Ischaemia after Haemodialysis Vascular Access Surgery. Nephrol Dial Transplant, 14, 297-300. https://doi.org/10.1093/ndt/14.2.297

[4] Wilbourn, A.J., Furlan, A.J., Hulley, W. and Ruschhaupt, W. (1983) Ischemic Monornelic Neuropathy. Neurology, 33, 447-451.

https://doi.org/10.1212/WNL.33.4.447

[5] Hye, R. and Wolf, Y. (1994) Ischemic Monomelic Neuropathy: An Under-Recognized Complication of Hemodialysis Access. Annals of Vascular Surgery, 8, 578582. https://doi.org/10.1007/BF02017415

[6] No Authors (2006) NKF-K/DOQI Clinical Practice Guidelinesfor Vascular Access: Update 2006. Am J Kidney Dis, 48, S176-S247.

[7] Larry, A. and Scher, M.D. (2009) Ischemic Monomelic Neuropathy. J Hand Surg, 35, 842-843.

[8] Michael, T.A. (2015) Ischemic Monomelic Neuropathy. http://emedicine.medscape.com/315915

Submit or recommend next manuscript to SCIRP and we will provide best service for you:

Accepting pre-submission inquiries through Email, Facebook, LinkedIn, Twitter, etc. A wide selection of journals (inclusive of 9 subjects, more than 200 journals)

Providing 24-hour high-quality service

User-friendly online submission system

Fair and swift peer-review system

Efficient typesetting and proofreading procedure

Display of the result of downloads and visits, as well as the number of cited articles

Maximum dissemination of your research work

Submit your manuscript at: http://papersubmission.scirp.org/

Or contact wjcs@scirp.org 